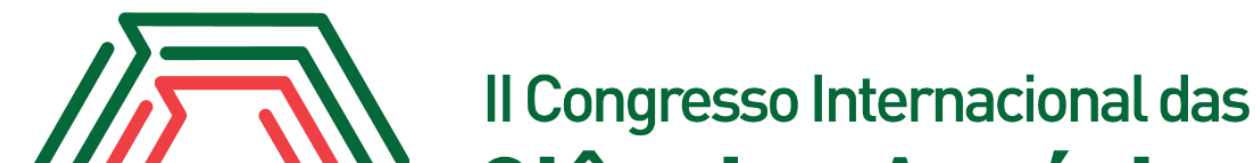 Ciências Agrárias COINTER - PDVAgro 2017
}

\section{SERVIÇOS DE ATER EM COMUNIDADES RURAIS: ASPECTOS DE IMPLANTAÇÃO}

\author{
Apresentação: Pôster
}

\begin{abstract}
Abner Henrique Santos Reis ${ }^{1}$; Larissa Tavares da Trindade ${ }^{2}$; Nubia Ribeiro Maria ${ }^{3}$; João Douglas Maciel Simões ${ }^{4}$; Fabio Haruki Hatano ${ }^{5}$
\end{abstract}

\section{Introdução}

O avanço da sociedade brasileira correlacionado ao desenvolvimento de suas cidades, atraiu atenção para as comunidades mais afastadas dos grandes centros. Este fato tornou-se fator primordial para subsidiar recursos e políticas públicas, que trouxe à tona a realidade vivida pelas comunidades rurais.

A Assistência Técnica e Extensão Rural (ATER), na esfera de governo, é um instrumento de política pública em projetos e programas voltados ao desenvolvimento rural. (LIMA et al., 2014). No Estado do Pará, a Emater-Pará é o órgão oficial nos serviços de ATER. Presta serviços especializados nas áreas de ciências agrárias e humanas, difundindo conhecimentos e informações tecnológicas no meio rural. Portanto, o objetivo deste trabalho foi conhecer os aspectos de aplicação nos serviços de ATER dentro de comunidades rurais, desenvolvidas pela Emater-Pa.

\section{Fundamentação Teórica}

Vários autores têm se dedicado ao estudo histórico-crítico da extensão rural, do seu discurso e do caráter de sua prática. Não raro, eles concluem que a extensão rural é uma atividade orientada para o desenvolvimento capitalista no campo, sendo sua prática determinada, ideologicamente, para

\footnotetext{
${ }^{1}$ Engenharia florestal, Universidade Federal Rural Da Amazônia, reisabner@hotmail.com

2 Engenharia florestal, Universidade Federal Rural Da Amazônia. larissa.eng.f@hotmail.com

${ }^{3}$ Engenharia florestal, Universidade Federal Rural Da Amazônia.nbia.ribeiro@gmail.com

${ }^{4}$ Engenharia florestal, Universidade Federal Rural Da Amazônia, douglasmacielpub@outlook.com

${ }^{5}$ Doutor em Biologia Ecologia, Universidade Federal Rural Da Amazônia. fhatano@gmail.com
} 
ser um processo educativo domesticador/excludente (CAPORA, 1991).

O modelo produtivo agropecuário adotado no Brasil a partir de 1960 foi implantado graças a uma ação conjunta e organizada pelo tripé: ensino, pesquisa e extensão, tendo como desenvolvimento as fases da extensão rural no Brasil. A primeira fase, chamada "humanismo assistencialista", prevaleceu desde 1948 até o início de 1960. A fase 2, "difusionismo produtivista", baseava-se na aquisição por parte dos produtores, de um pacote tecnológico modernizante, com uso intensivo de capital. A fase 3, "humanismo crítico", teve início em 1980 e percorre até os dias atuais. No entanto, o país vive uma nova proposta de extensão rural, que preconizava a construção de uma "consciência crítica" nos extensionistas (ADM, 2005).

\section{Metodologia}

Foi realizada uma pesquisa de campo, com caráter exploratório na empresa de assistência técnica e extensão rural, estado do Pará, regional Marituba. O local foi escolhido como foco de coleta de dados. Como instrumento de coleta de dados utilizou-se a aplicação de um questionário estruturado. $\mathrm{O}$ alvo da pesquisa foi o extensionista, servidor público do órgão, na regional citada a cima, totalizando uma amostra de 16 funcionários.

\section{Resultados e Discussões}

A respeito de como avaliavam os obstáculos para o extensionista aplicar os serviços de ATER pública, os entrevistados indicaram os principais possíveis entraves, descritos no Gráfico 1. 
Gráfico 1: Entraves para os serviços de ATER. Fonte: Própria

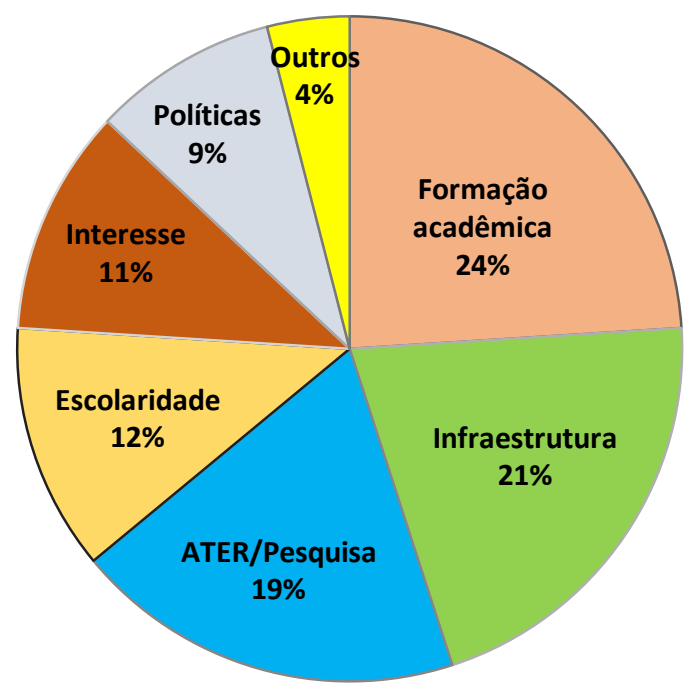

$\square$ Formação acadêmica $\square$ Infraestrutura $\square$ ATER/Pesquisa $\square$ Escolaridade $\square$ Interesse $\square$ Políticas $\square$ Outros

A deficiência na formação acadêmica dos futuros profissionais da extensão rural, surge como o maior fator delimitante para uma ATER eficaz, representando uma parcela de $24 \%$ nos entraves apontados. Neste caso, as universidades precisam voltar atenção ao trabalho de extensão acadêmica, de modo que os futuros profissionais tenham maior contato com a realidade do campo. Outro ponto é rever a grade curricular de modo que se tenha uma visão mais sistêmica e não voltada prioritariamente para o agronegócio.

A infraestrutura de atendimento dos agricultores, é outro fator apontado pelos entrevistados (21\%). Este resultado indica a que falta de condições (logística e operacional) para que o extensionista realize suas ações junto aos agricultores familiares é um grande limitante para os serviços de ATER, pois restringe a área de atuação do extensionista e inviabiliza um atendimento continuado, fundamental para se conseguir bons resultados no campo.

A falta de uma maior interação entre a ATER e a pesquisa, representa $19 \%$ dos entraves citados pelos entrevistados. Isto se dá, em função de que muitas tecnologias são geradas pela pesquisa e não chegam até o beneficiário principal que é a agricultor, tendo em vista o distanciamento entre os atores (pesquisa e extensão). Em outros casos as tecnologias não são adequadas para a agricultura familiar pois não tiveram a participação da extensão ou dos agricultores sobre suas realidades.

A falta de interesse e o baixo nível de escolaridade do produtor rural $(11 \%$ e $12 \%$, respectivamente), aparecem como entraves também. Segundo os entrevistados, a falta de interesse decorre, em geral, pelo fato de que inúmeros projetos e programas que foram divulgados ou iniciados 
e não tiveram continuidade, que gerou expectativas e que acabaram frustrando as famílias. Quanto a questão da escolaridade, de fato é um limitante, principalmente para as ações de capacitação, porém existem estratégias que podem minimizar este problema, como algumas metodologias de ATER (demonstração de método, excursões, intercâmbios, Unidades demonstrativas e etc).

A política agrícola no Estado representa cerca de $9 \%$ de influência na implementação dos serviços de ATER segundo a avaliação dos entrevistados. Existe um sombreamento muito grande de ações dos diversos órgãos do Estado, quando os esforços deveriam ser maximizados com o estabelecimento de parcerias e uma gestão mais qualificada dos programas e projetos implementados.

Quando abordados sobre os aspectos econômicos, sociais e ambientais que acarretam os serviços de ATER, foi possível observar que a EMATER-PA faz o acompanhamento das famílias para que ocorra o gerenciamento destes aspectos. De acordo com os entrevistados, as famílias atendidas pelos escritórios locais são devidamente cadastradas para que se tenha minimamente um histórico de atendimento, além de respaldar o planejamento das ações de ATER no município.

No entanto, a grande maioria dos entrevistados, não soube dizer a porcentagem de incremento de produtividade dos agricultores familiares após a intervenção da EMATER. O fato é que nem sempre o profissional extensionista fica a par dessas informações e a eficiência do dos serviços depende muito do agricultor colocar em prática as orientação repassadas. Segundo Rodrigues et al. (2007), a viabilidade econômica nos sistemas florestais depende não apenas de um plano de manejo adequado ou a intensificação do mesmo, mas também do valor do produto para o consumidor final.

No contexto social, a importância da implementação dos serviços de ATER para os entrevistados, surge como via para a inclusão das famílias nas políticas públicas e valorização do trabalho e da produção. Segundo Betta (2015), conhecer os gargalos do acesso da extensão rural agroecológica por parte dos agricultores familiares produz informações úteis para serem utilizadas pelos órgãos públicos envolvidos, esperando-se que futuramente tais demandas possam ser atendidas.

No contexto econômico, os entrevistados apontaram, entre outros fatores, a agregação de valor à produção, acesso a mercados diferenciados para venda da produção, tem como resultado um incremento na renda. Existem ganhos econômicos indiretos para o agricultor, à exemplo, o Programa Nacional de Fortalecimento da Agricultura Familiar, que disponibiliza a cada plano safra recursos para financiamento de crédito rural. Para acessar o programa o agricultor precisa atender algumas exigências, dentre as quais a Declaração de Aptidão ao Pronaf - DAP (que é realizado aos agricultores cadastrados pela Emater), que inclusive lhe credencia para acessar outros benefícios, como a casa 
própria através do Programa Nacional de Habitação Rural (PNHR), aposentadoria, venda para a merenda escolar pelo Programa Nacional de Alimentação Escolar (PNAE), dentre outros.

Outro fato importante a se destacar, quanto a questão ambiental, é que em grande parte das culturas de ATER, são implantados sistemas agroflorestais. Segundo VIEIRA et al. (2007), na Amazônia, os sistemas agroflorestais associados à agricultura familiar, implementam frutíferas tradicionais da região, o que favorece a sucessão das espécies nativas.

\section{Conclusões}

Para aplicação eficiente da política de ATER, é necessária capacitação do profissional que atua nesta atividade, investimentos para intensificação de programas de assistência técnica, um maior estreitamento entre a pesquisa de novas tecnologias e a praticidade de implementação destas no setor rural e sem dúvida nenhuma a interação agricultor e extensionista.

\section{Referências}

ADM - Artigo de Divulgação na Mídia, Embrapa Pantanal, Corumbá-MS, n. 77, p.1-3. abr. 2005.

BETTA, B, M, D. Agricultura familiar agroecológica e os desafios da extensão rural no Oeste Catarinense. 81 f. Trabalho de Conclusão de Curso (Graduação em Agronomia). Universidade Federal de Santa Catarina, UFSC, Santa Catarina, 2015.

CAPORAL, F. R. A EXTENÇÃO RURAL E OS LIMITES À PRATICA DOS EXTENSIONISTAS DO SERVIÇO PÚBLICO. Dissertação. Santa Maria, 1991.

LIMA, F.A.X.; VARGAS, L.P.; SOUZA, G.M.B.; JOTA, T.A.F.\& WIZNIEWSKY, J. G. Extensão rural, comunicação e mobilização social: experiências do IPA junto aos agricultores familiares de Pernambuco - v. 8, n. 2 - Ago - 2014.

RODRIGUES, E.R. et al. Avaliação econômica de sistemas agroflorestais implantados para recuperação de reserva legal no pontal do Paranapanema, São Paulo. Revista Árvore, v. 31, n. 5, p. 941-948, 2007.

VIEIRA, T. A. et al. Sistemas agroflorestais em áreas de agricultores familiares em Igarapé-Açu, Pará: caracterização florística, implantação e manejo. Acta Amazonica, v. 37, n. 4, 549-558, 2007. 